\title{
Experimental and Numerical Evaluation of Rock Dynamic Test with Split-Hopkinson Pressure Bar
}

\author{
Kang Peng, ${ }^{1,2}$ Ke Gao, ${ }^{3}$ Jian Liu, ${ }^{3}$ Yujiao Liu, ${ }^{3}$ Zhenyu Zhang, ${ }^{1,2}$ Xiang Fan, ${ }^{4}$ Xuyan Yin, \\ Yongliang Zhang, ${ }^{5}$ and Gun Huang ${ }^{1,2}$ \\ ${ }^{1}$ State Key Laboratory of Coal Mine Disaster Dynamics and Control, Chongqing University, Chongqing 400044, China \\ ${ }^{2}$ College of Resources and Environmental Science, Chongqing University, Chongqing 400030, China \\ ${ }^{3}$ College of Safety Science and Engineering, Liaoning Technical University, Liaoning 125105, China \\ ${ }^{4}$ School of Highway, Chang'an University, Xian 710064, China \\ ${ }^{5}$ Automotive School, Qingdao Technological University, Qingdao, Shandong 266520, China
}

Correspondence should be addressed to Kang Peng; pengkang@cqu.edu.cn

Received 12 January 2017; Revised 4 May 2017; Accepted 14 May 2017; Published 12 June 2017

Academic Editor: Francesco Caputo

Copyright (C) 2017 Kang Peng et al. This is an open access article distributed under the Creative Commons Attribution License, which permits unrestricted use, distribution, and reproduction in any medium, provided the original work is properly cited.

\begin{abstract}
Feasibility of rock dynamic properties by split-Hopkinson pressure bar (SHPB) was experimentally and numerically evaluated with ANSYS/LS-DYNA. The effects of different diameters, different loading rates, and different propagation distances on wave dispersion of input bars in SHPB with rectangle and half-sine wave loadings were analyzed. The results show that the dispersion effect on the diameter of input bar, loading rate, and propagation distance under half-sine waveform loading is ignorable compared with the rectangle wave loading. Moreover, the degrees of stress uniformity under rectangle and half-sine input wave loadings are compared in SHPB tests, and the time required for stress uniformity is calculated under different above-mentioned loadings. It is confirmed that the stress uniformity can be realized more easily using the half-sine pulse loading compared to the rectangle pulse loading, and this has significant advantages in the dynamic test of rock-like materials. Finally, the Holmquist-Johnson-Concrete constitutive model is introduced to simulate the failure mechanism and failure and fragmentation characteristics of rock under different strain rates. And the numerical results agree with that obtained from the experiment, which confirms the effectiveness of the model and the method.
\end{abstract}

\section{Introduction}

Understanding the dynamic characteristics of rocks under higher strain rate is significant for either engineering stability or rock fragmentation efficiency. Since the first use of split-Hopkinson pressure bar (SHPB) system by Kolsky (1949), extensive studies have been performed to investigate dynamic mechanical properties of different materials. So far, SHPB experimental technique has been widely used in geotechnical evaluations and substantial efforts have been made to study dynamic mechanical properties of rocks [19]. The result shows that the dynamic compressive strength and dynamic tensile strength of lands measurement using SHPB are valid and reliable by Dai et al. [10]. Currently, there is an increasing demand for better experimental equipment and higher experimental accuracy on this aspect. Numerical simulation is an important way to improve and optimize the SHPB experimental technique. Firstly, the SHPB experiment technology can be perfected and supplemented by using numerical simulation. The sensitivity coefficient of the strain gauge attached to SHPB bars needs to be statically calibrated prior to relevant tests. By comparing the accurate numerical result with the experimental waveform, the coefficient can be obtained to reduce the number of errors. Xu et al. confirmed the validity of this DEM model to reproduce the dynamic fracturing and the feasibility to simultaneously measure key dynamic rock fracture parameters, including initiation fracture toughness, fracture energy, and propagation fracture toughness [11]. The damage and rupture process of coal-rock is accompanied by acoustic emission (AE) by Wen et al. [12]; the results show that coal-rock's size influences the uniaxial compressive strength, peak strain, and elastic modulus of 


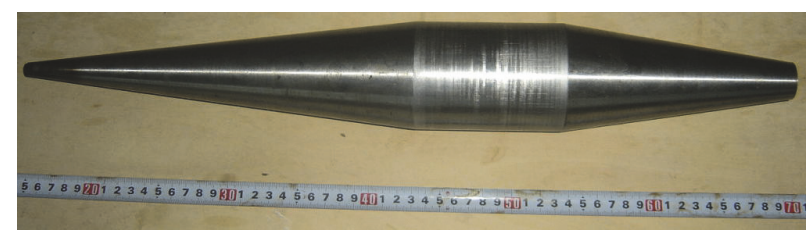

FIGURE 1: Striker of SHPB measurement equipment $(\varphi, 50 \mathrm{~mm})$.

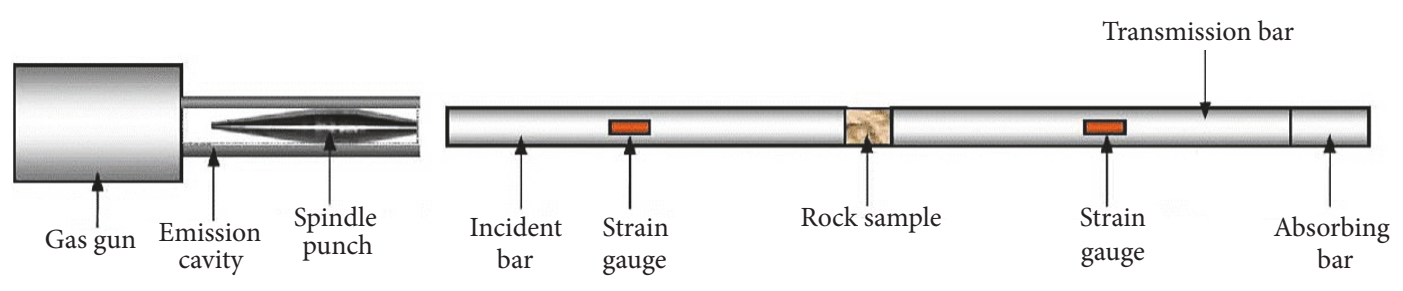

FIGURe 2: Typical SHPB testing device.

itself. Assessing via discrete element method shows that the loading-rate-dependent cracking profiles of chevronnotched specimens cannot be ignored in order to determine accurately the fracture toughness of rock in dynamic mode I [13]. The bedding effect on the coal behavior at static strain rate is more prominent than that at dynamic strain rate [14]. A two-dimensional axisymmetric numerical analysis is used to compute all components of the stress, strain, and strain rate tensors at each mesh point within the specimen and the elastic bars by Bertholf and Karnes [15]. The result shows that inertia and friction between the specimen and the elastic bars affected the response of specimen differently because of different length-to-diameter ratios, and serious stress and strain nonuniformity exists when the ends are not lubricated. To efficiently study and analyze the mechanism behind major stope disasters, a method based on monitoring the stress and displacement of stopes was adopted, and a method of ascertaining stope stability based on qualitative identification of the dynamics was further proposed. At the same time, the relations and differences between rockburst in the coal mine and rockburst in the metal mine were studied. Coal mine rockburst is divided into two types: static loading type during roadway excavation process and dynamic loading type during mining face advancing [16-18]. Secondly, the shape of the pulse and the materials of the bars have attracted attention recently $[19,20]$. The result shows that, by virtue of the ramped wave loading, the force equilibrium of the specimen can be effectively achieved and the rupture is precisely measured to synchronize with the peak force, both of which guarantee the quasi-static data reduction method employed to determine the dynamic flexural strength by $\mathrm{Xu}$ et al. [21]. A series of rock cutting tests were performed to investigate the influence of back rake angle on the critical failure mode transition depth by Zhou et al. [22]. It is found that the critical failure mode transition depth increases with the back rake angle. This suggests that the brittle fracture failure induced at large depth of cut can be inhibited by increasing the back rake angle. Cutting at a small back rake angle, on the other hand, is desirable if minimization of the cutting energy is required in the application.

Although the results of numerical simulation demonstrate that rectangular wave and trapezoidal wave applied performed perfectly, simulation analysis was still complicated. It barely takes action to load with sine wave. In this study, the dynamic compressive properties of rocks were experimentally and numerically evaluated using ANSYS/LSDYNA. And for numerical simulation analysis, an approach, which uses sine wave, was put into use.

\section{Experimental Apparatus}

2.1. Impact Ram. The rectangular waveform loading was adopted in the conventional SHPB experiment on rocks, and the obtained curves were smoothly processed. However, large experimental errors exist for rock-like materials [7]. In order to eliminate this error, $\mathrm{Li}$ et al. [23, 24] proposed a half-sine waveform loading instead of the conventional rectangular waveform loading in SHPB tests. The novel striker (Figure 1) was designed by back-design method and Numerical Simulation Software [8, 25-28], whose material is the same as the bars.

2.2. Experimental Apparatus and Principle. A typical test system consists of a gas gun, an input bar, an output bar, and the specimen as shown in Figure 2. Figure 3 shows the sketch of the experiment devices.

When the striker impacts the free end of the input bar, an elastic compressive stress pulse is produced which propagates in the input bar toward the specimen. When the pulse reaches the specimen, it is partially reflected, with one part back into the input bar and the rest transmitted into the output bar through the specimen.

\section{Computational Model and Method}

3.1. FEM Model. In the SHPB apparatus, the bars and specimens are designed into cylinders, and they are coaxial. 


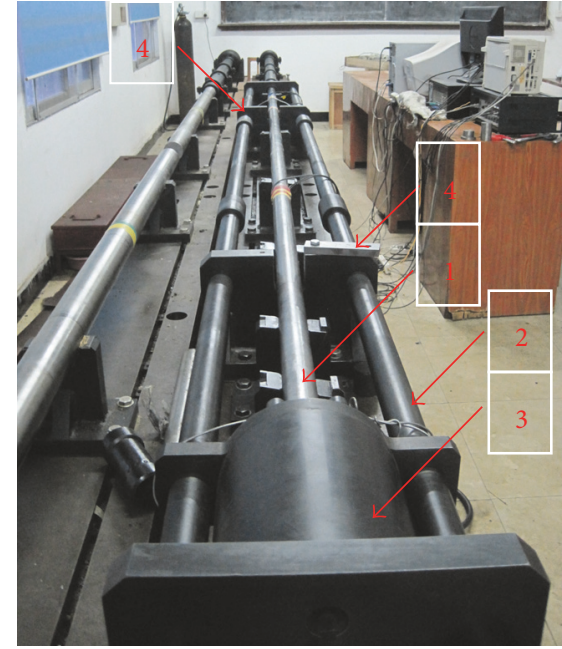

FIGURE 3: The sketch of the experiment devices (1, stress transfer device, 2, axial compression load outreach framework, 3, axial compression loading device, and 4, bearing of the axial compression loading outreach framework).

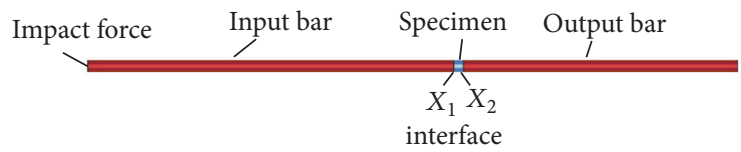

FIGURE 4: Modeling of the SHPB apparatus.

The input and output bars are made by $40 \mathrm{Cr}$ alloy and the length is $200 \mathrm{~mm}$ and $150 \mathrm{~mm}$, respectively. The diameter and the length of the specimens can be changed according to different needs. Surface contacts are adopted between bars and specimens on condition that the effect of friction is neglected.

3.2. Numerical Modeling Development. The model is discretized by three-dimensional 8-node elements with reduced integration and hourglass control (SOLID164). Totally, 37042 elements and 46293 nodes are constructed in the model (Figure 4), 21600 elements for the input bar, 16200 elements for the output bar, and 1080 elements for the specimen.

3.3. Computational Method. Because the yield strength of the Hopkinson bars outclasses that of specimen, the finite element models of the Hopkinson bars are assumed to be a linear elastic material. Poisson ratio, density, and elastic modulus for the bars are $0.30,7795 \mathrm{~kg} / \mathrm{m}^{3}$, and $210 \mathrm{GPa}$, respectively.

Rock is a typical quasi-brittle, flaws-embedded material. The deformation failure of rock is usually accompanied with nonuniform, noncontinuous, and large deformation which makes it a very complex highly nonlinear problem because of the particularity and complexity of the rock material.

The Holmquist-Johnson-Concrete constitutive equation is used to model rock-like material in the finite element simulation, which makes it possible to simulate large strains,

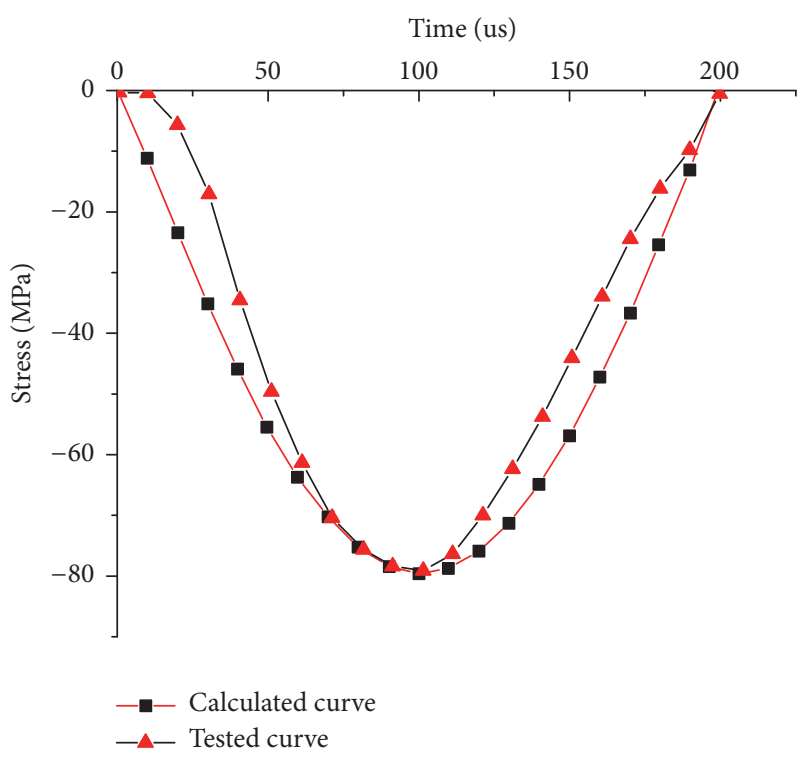

FIGURE 5: The incident pulse.

TABLE 1: Mechanical properties of the rock.

\begin{tabular}{|c|c|}
\hline Properties & value \\
\hline Type of rock & Sandstone \\
\hline$\rho\left(\mathrm{kg} / \mathrm{m}^{3}\right)$ & 2630 \\
\hline G/GPa & 6.00 \\
\hline$A$ & 0.71 \\
\hline$B$ & 1.84 \\
\hline C & 0.007 \\
\hline$N$ & 1.00 \\
\hline$\dot{\varepsilon}_{0} / \mathrm{s}^{-1}$ & $2.9 \times 10^{-5}$ \\
\hline$\varepsilon_{f \min }$ & 0.01 \\
\hline$S_{\max }$ & 5.0 \\
\hline$P_{\mathrm{cr}} / \mathrm{GPa}$ & 0.035 \\
\hline$\mu_{\mathrm{cr}}$ & $8.0 \times 10^{-4}$ \\
\hline$P_{\text {lock }} / \mathrm{GPa}$ & 1.035 \\
\hline$\mu_{\text {lock }}$ & 0.100 \\
\hline$D_{1}$ & 0.045 \\
\hline $\mathrm{D}_{2}$ & 1.00 \\
\hline Tensile strength/MPa & 13.8 \\
\hline$f_{c} / \mathrm{MPa}$ & 91.36 \\
\hline$K_{1} / \mathrm{GPa}$ & 85 \\
\hline$K_{2} / \mathrm{GPa}$ & -171 \\
\hline$K_{3} / \mathrm{GPa}$ & 208 \\
\hline
\end{tabular}

A: standard cohesion strength; $B$ : standard pressure hardening coefficient; $C$ : the coefficient of strain rate; $N$ : pressure hardening index; $D_{1} / D_{2}$ : damage constant; $P_{\text {cr }} / P_{\text {lock }}$ : Elastic peak point/the pressure of crack compaction point; $\mu_{\text {cr }} / \mu_{\text {lock}}$ : bulk strain; $K_{1}, K_{2}$, and $K_{3}$ : rock constant; $f_{c}$ : compressive strength; $S_{\max }$ : ultimate strength; $\varepsilon_{f \min }$ : the minimum tensile strain at break; $\dot{\varepsilon}_{0}$ : reference rate of strain.

high strain rates, and high pressure in rock-like materials. Mechanical properties used for the specimens are listed in Table 1 [29]. 


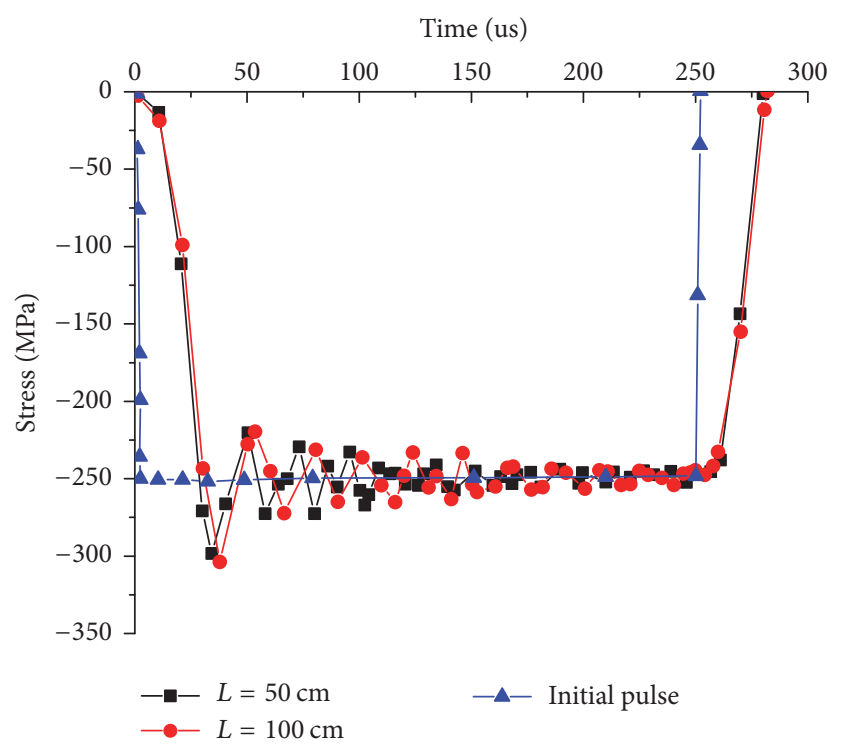

(a) Rectangular waveform pulse loading

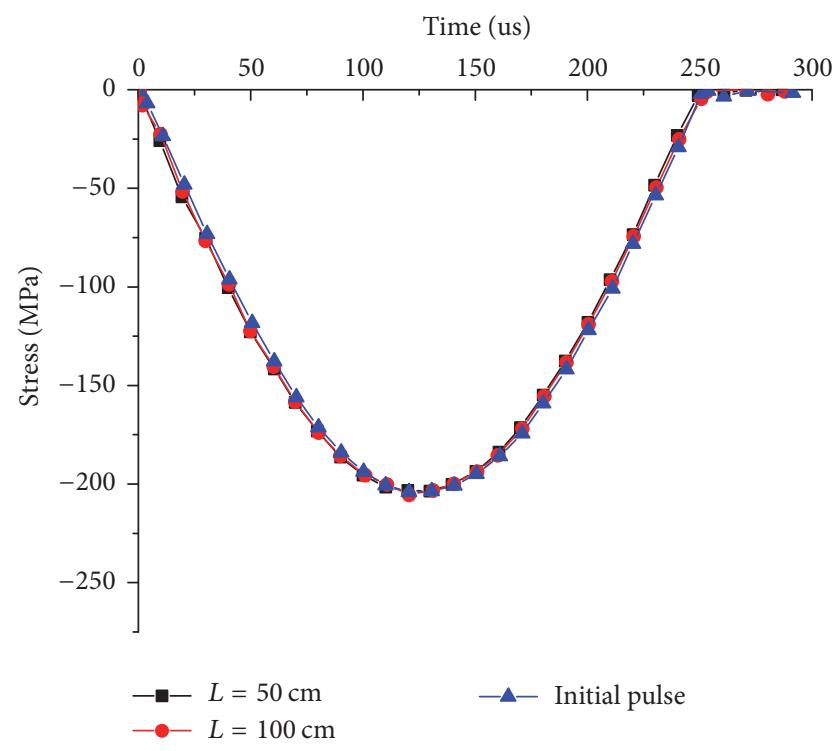

(b) Half-sine waveform pulse loading

FIgURE 6: Time-history of stress pulses at different propagation distances $(L)$ away from the impact end of the input bar.

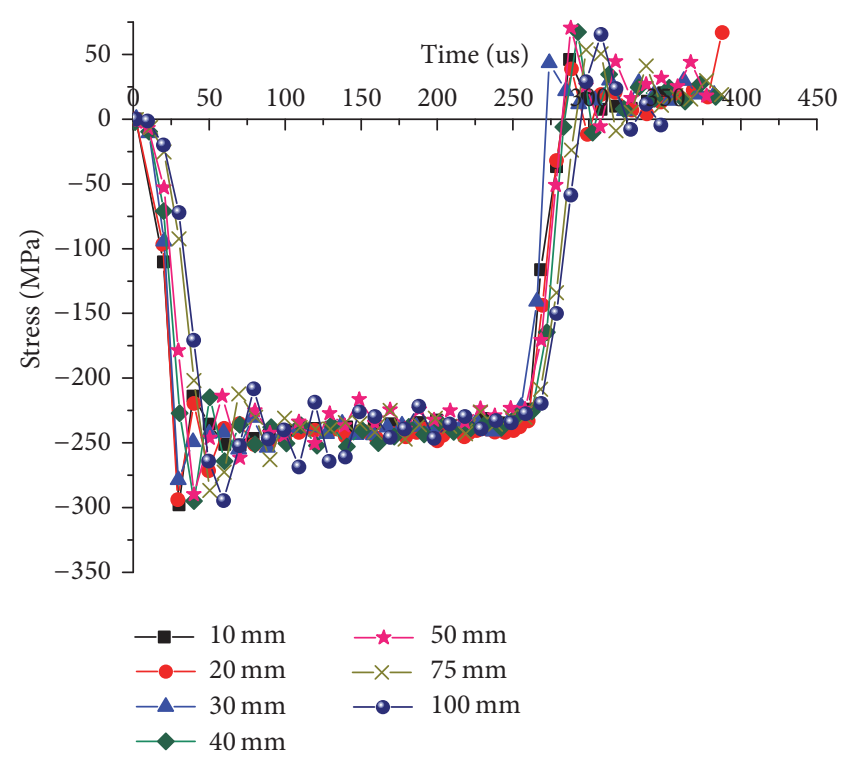

(a) Rectangular waveform pulse loading

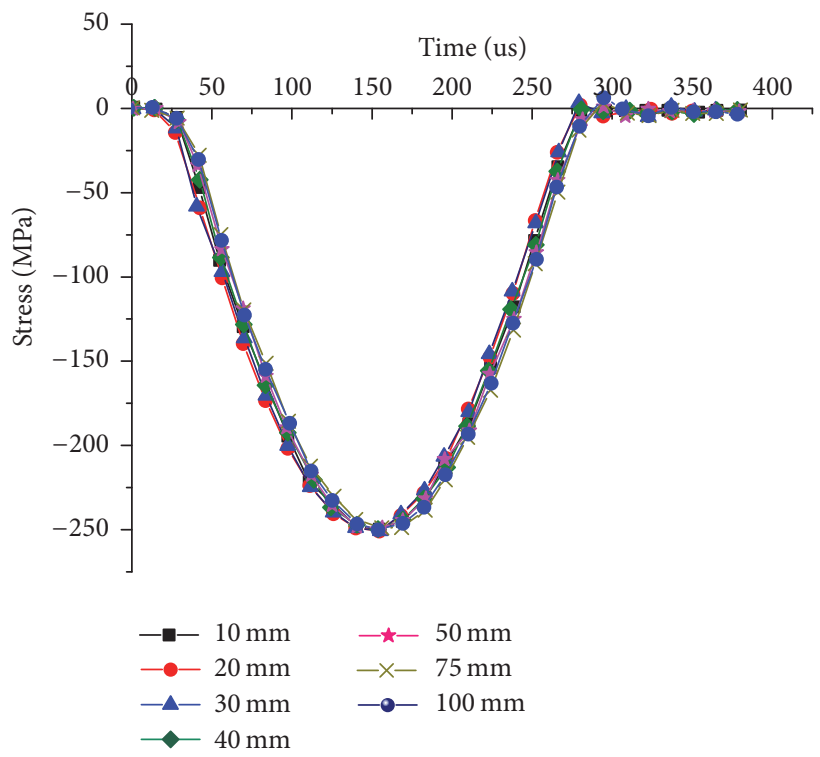

(b) Half-sine waveform pulse loading

FIgURE 7: Time-history of stress pulses at different diameters $(L=100 \mathrm{~mm})$.

3.4. Loading and Constraint. The constraint is applied on the symmetrical surfaces. The axial constraint is applied on the center nodes of the bars and specimens. Other surfaces of the coaxial system of the model are all stress-free.

In the SHPB test, the incident pulse is normally provided by the effect of a striker on the incident bar. The incident wave is determined by the shape of the striker. While the length of the striker can change that of the incident pulse, it has limited impact on the incident wave. In order to easily control the waveform and facilitate the analysis, the direct stress loading mode, pulse duration, and stress amplitude are designed for different needs (Figure 5). In this study, two waveforms, rectangular waveform and half-sine waveform, are used for analogy calculation.

\section{Results and Analysis}

4.1. The Choice of the Rational Waveform Loading of Rock with SHPB. In order to investigate the rational waveform loading of rock with SHPB, both rectangle and half-sine 


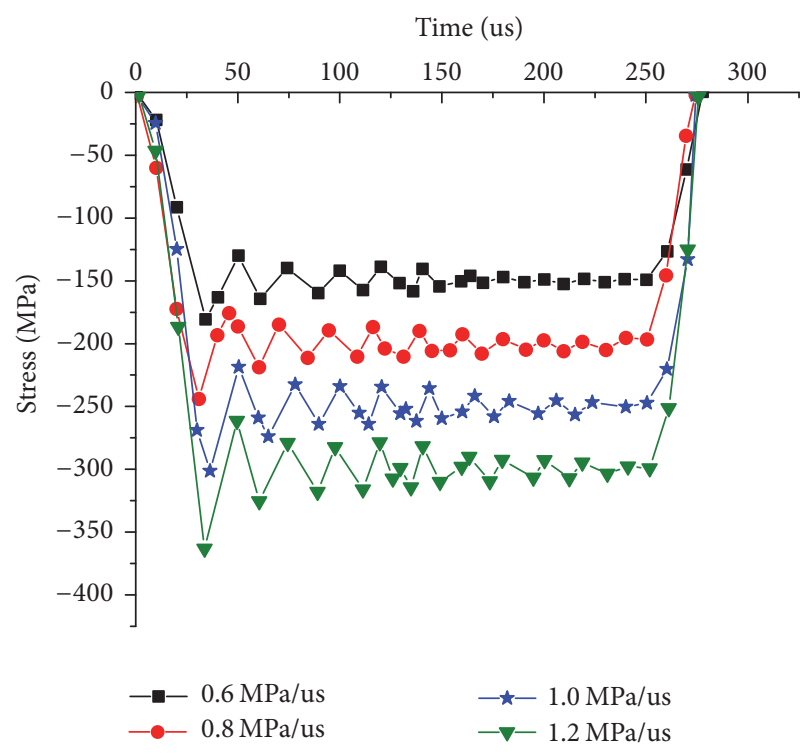

(a) Rectangular waveform pulse loading

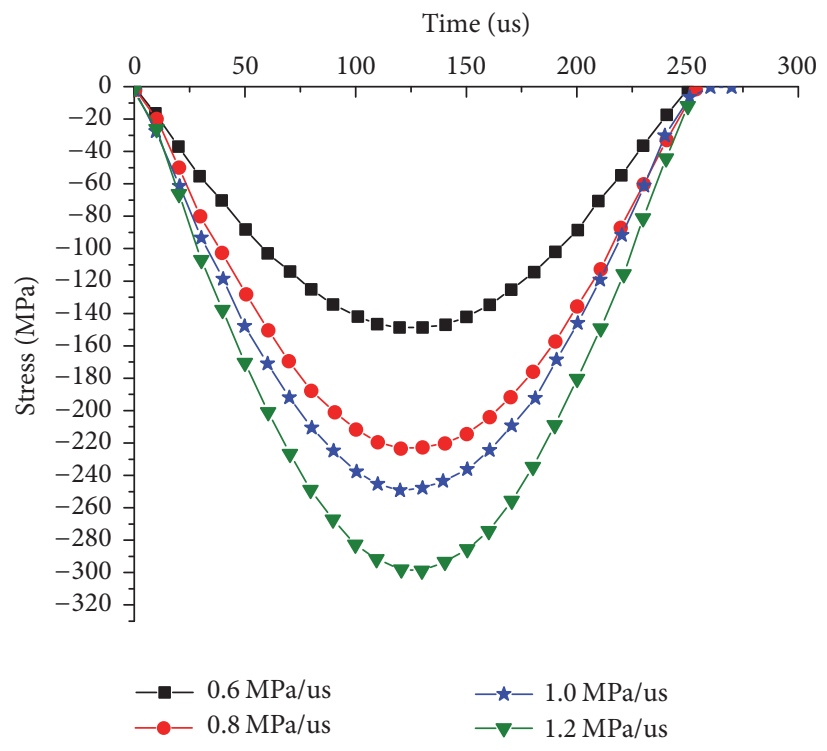

(b) Half-sine waveform pulse loading

FIGURE 8: Time-history of stress pulses at different loading rates.

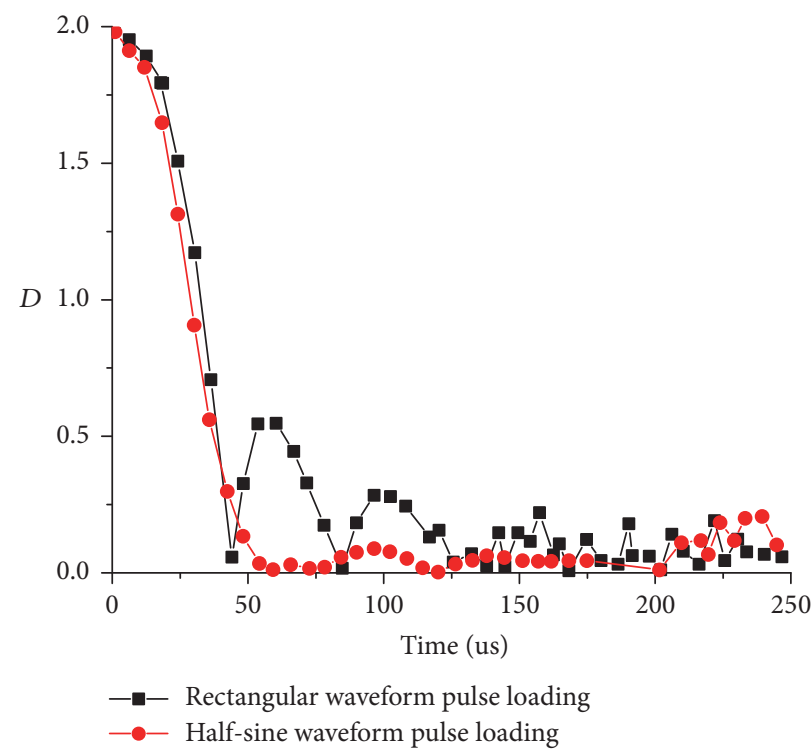

FIGURE 9: Variation curve of stress equilibrium equations factor (the diameter is $50 \mathrm{~mm}$, and the length-diameter ratio of specimen is 1).

waveform loadings are chosen. The wave dispersion and the stress uniformity process under two input wave loadings are analyzed by conducting large-diameter SHPB test.

4.1.1. Numerical Analysis of Wave Dispersion. It is shown that the dispersion phenomenon occurs when the stress pulse transmits along the input bar in conventional SHPB, which can cause severe oscillation of the ultimate dynamic constitutive response of materials [7, 15, 30, 31]. Merle and Zhao suggest a correct method, which can find potential error of frequency components [32]. Zhao and Gary proposed a direct calculation of dispersion relations, which can accurately analyze the dispersion effect and not consider the stress uniformity [33]. To study the influence of wave dispersion on the stress distribution across the bar section at different radii $(10 \mathrm{~mm}, 20 \mathrm{~mm}, 30 \mathrm{~mm}, 40 \mathrm{~mm}, 50 \mathrm{~mm}$, $75 \mathrm{~mm}$, and $100 \mathrm{~mm}$ ), the stress distribution in input bar (2.0 $\mathrm{m}$ in length) under different loadings was numerically analyzed. The material parameters used in the finite element model (Figure 4) for the bar are listed in Table 1. The timestress curves are recorded at two positions which are $50 \mathrm{~cm}$ and $100 \mathrm{~cm}$ from the loading interface, respectively.

Figure 6 shows typical stress pulses recorded under both rectangle and half-sine waveform loadings. It is apparent 


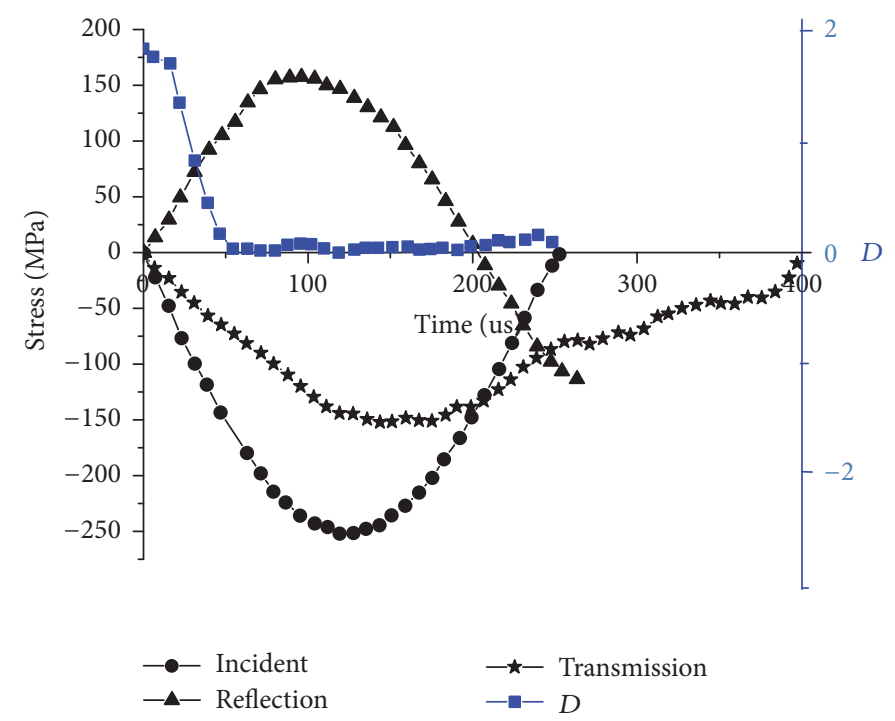

(a) Half-sine waveform pulse loading

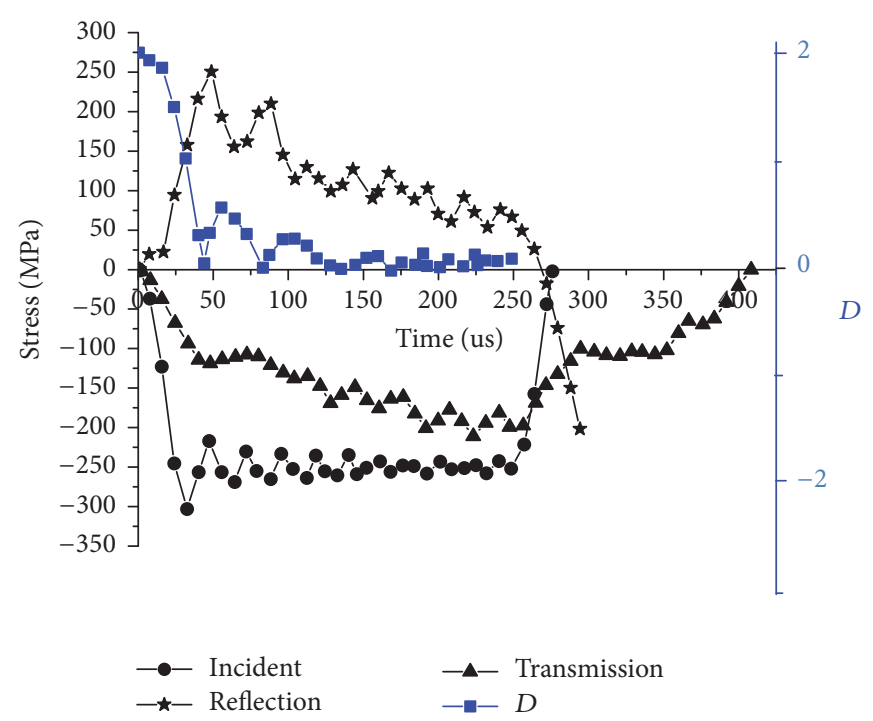

(b) Rectangular waveform pulse loading

FIGURE 10: Stress pulses and stress equilibrium equations factor.

that both the rise time of the stress front and oscillation amplitude increased with the wave propagation distance as shown in Figure 6(a), and the high frequency oscillations and oscillation amplitude of wave became stronger with the increase of bar diameter.

It is also shown in Figure 7 that the higher the loading rate is, the more serious the $\mathrm{P}-\mathrm{C}$ oscillation is, thus making it impossible to obtain proper dynamic mechanical properties. However, the oscillation can be eliminated when the halfsine waveform pulse is loaded (see Figure 8), and there was absence of oscillation in the incident wave with the range of loading rate.

The reason of the dispersion phenomenon is that rectangle wave is of many different frequencies and harmonics.
Supposing that the time period is $\tau$, which denotes the rectangular wave, the formula can be expanded to the following equation according to Fourier class [34]:

$$
\begin{aligned}
\sigma_{\tau}(t) & =\frac{4}{\pi} \sum_{i=1}^{n} \sin \left[\frac{2 i-1}{\tau} \pi t\right] \quad i=1,2, \ldots, n \\
w_{i} & =\frac{(2 i-1)}{\tau} \pi \propto f\left(\frac{1}{\lambda_{i}}\right) .
\end{aligned}
$$

For this waveform, even the front main harmonic can guarantee that $r / \lambda \leqslant 1(i=1,2, \ldots, k)$; there will always be numerous high-harmonic items behind, where velocity $c_{P}<c_{0}$ will occur at the time of high-frequency items; then 


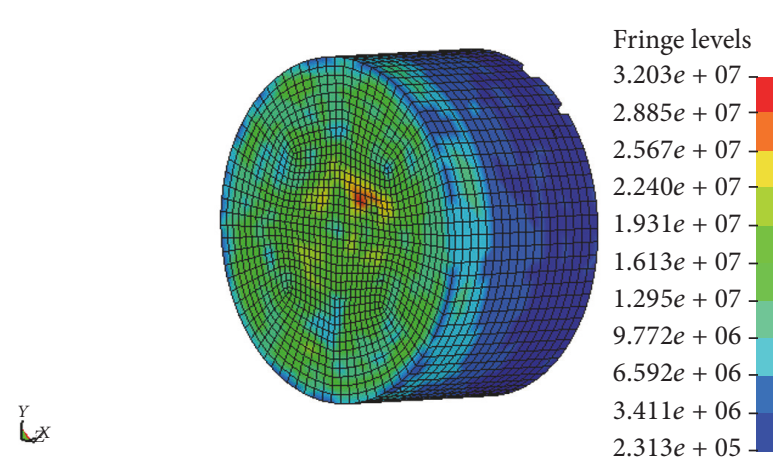

$125 \mu \mathrm{s}$

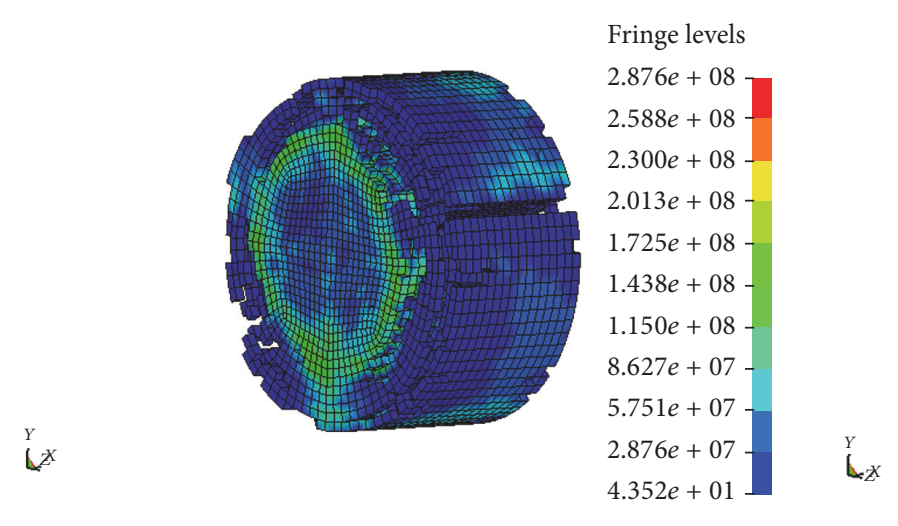

$142 \mu \mathrm{s}$

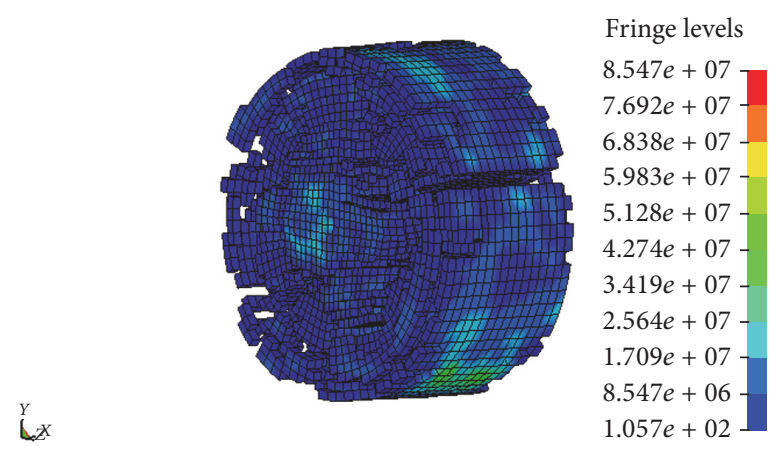

$156 \mu \mathrm{s}$

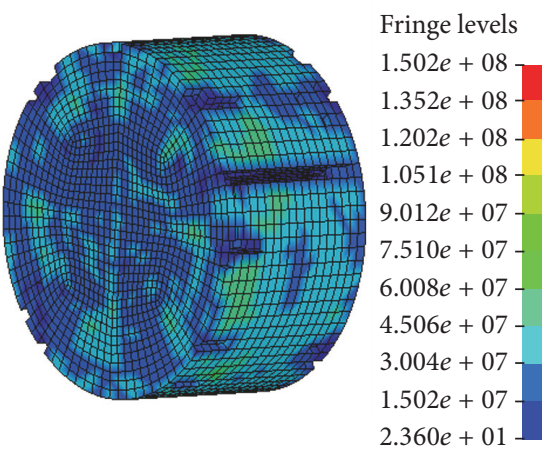

$131 \mu \mathrm{s}$

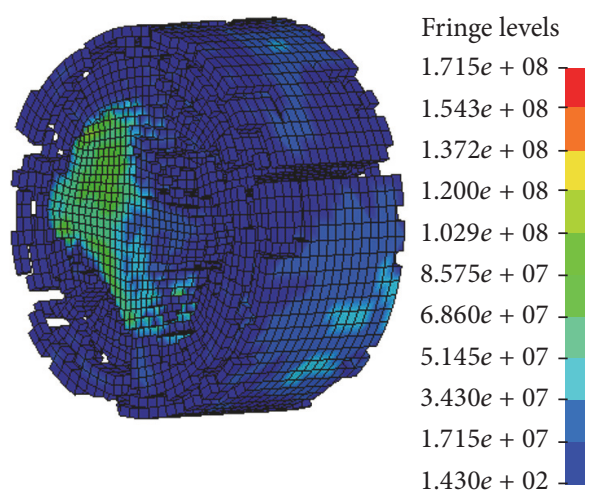

$146 \mu \mathrm{s}$

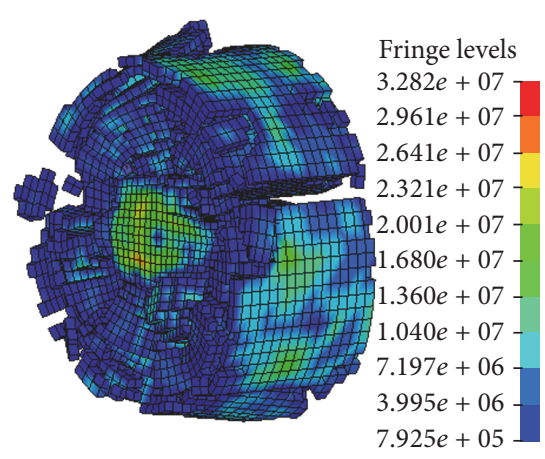

$300 \mu \mathrm{s}$

FIGURE 11: Numerical fracture process (the average strain rate is $52 \mathrm{~s}^{-1}$ ).

during the rod transmission process, it will certainly lead to the high-frequency dispersion at the first part of the wave. Meanwhile the single-frequency half-sine waves, as long as the bar radius meets the one-dimensional stress conditions (when $r / \lambda \ll 1, c_{P} \approx c_{0}$, that is, to meet the one-dimensional stress conditions), will not produce geometric dispersion during the wave propagation.

4.1.2. Correlation between the Stress Uniformity and the Incident Pulse. Accuracy of the SHPB test is based on the assumption of stress and strain uniformity within the specimen, which, however, is not always satisfied in an actual
SHPB test due to the existence of some unavoidable negative factors, for example, friction and specimen size effects.

To quantify the stress uniformity process, the coefficient of the axial stress uniformity, which was proposed by Zencker and Clos [35], is defined as

$$
D=2\left|\frac{\sigma_{z}^{(a)}-\sigma_{z}^{(b)}}{\sigma_{z}^{(a)}+\sigma_{z}^{(b)}}\right|
$$

where $\sigma_{z}^{(a)}$ and $\sigma_{z}^{(b)}$ describe the stress at $X_{1}$-interface and $X_{2}$ interface of specimen, respectively. 


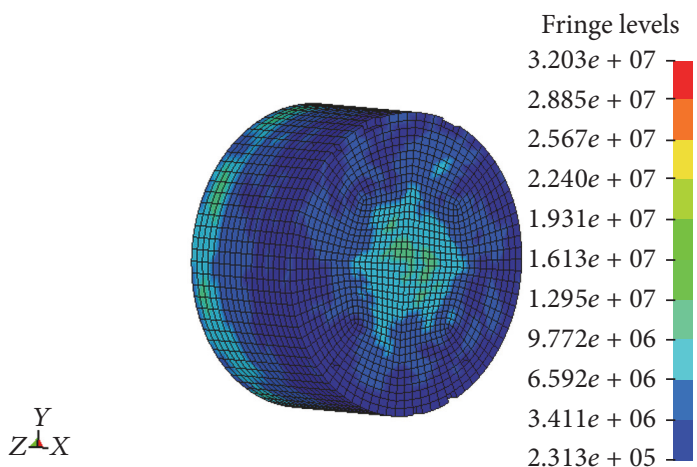

$125 \mu \mathrm{s}$

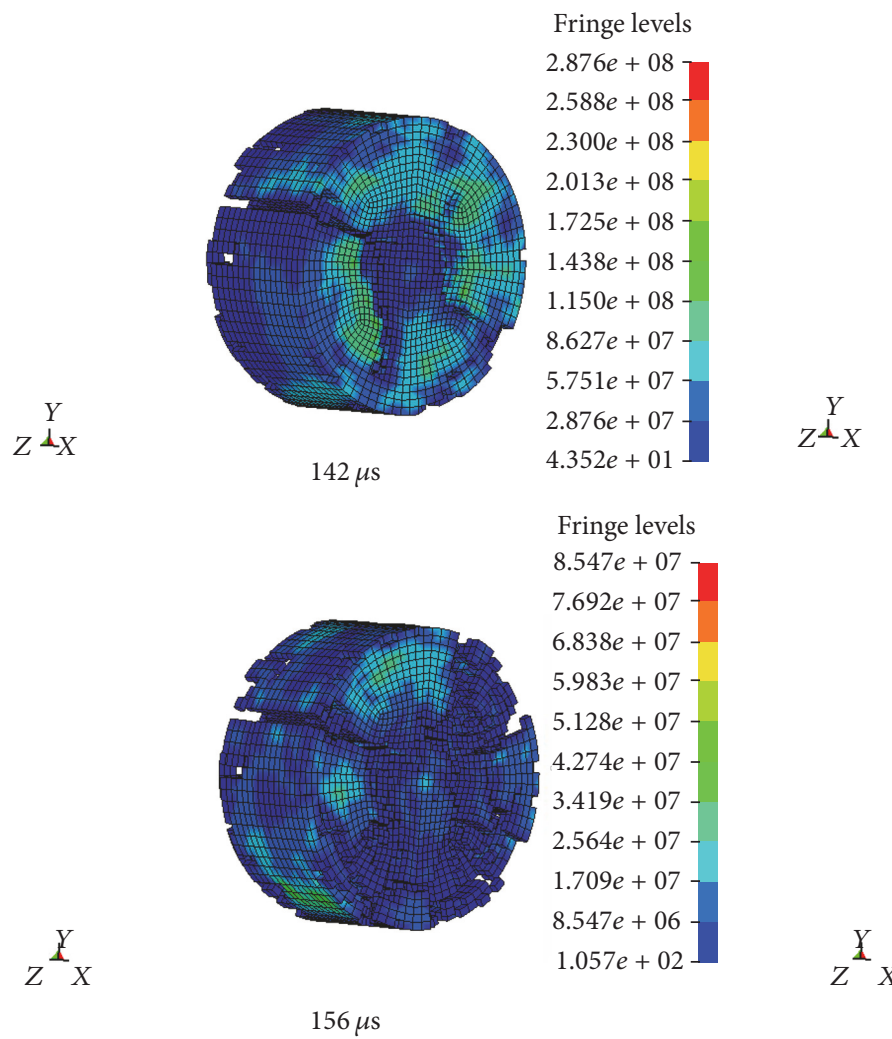

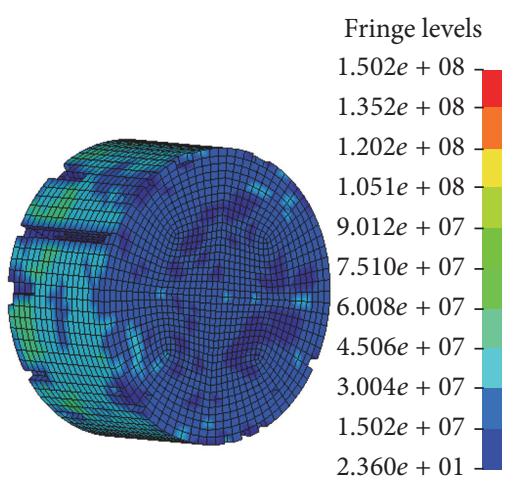

$131 \mu \mathrm{s}$

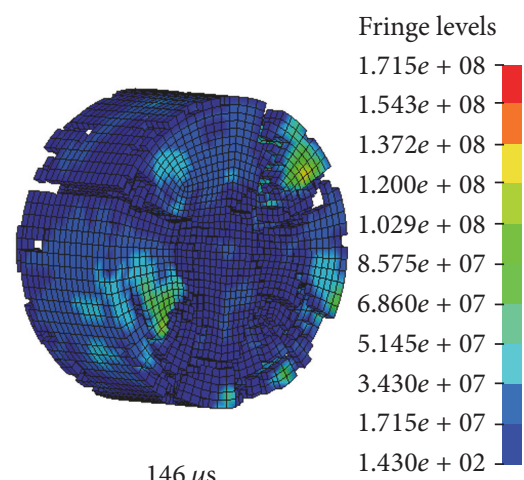

Fringe levels

$3.282 e+07$

$2.961 e+07$

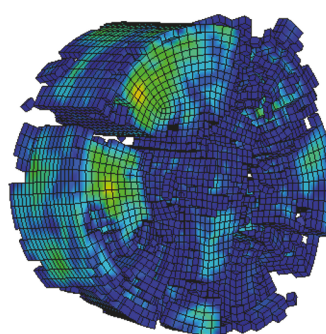

$2.641 e+07$

$2.321 e+07$

$2.001 e+07$

$1.680 e+07$

$1.360 e+07$

$1.040 e+07$

$7.197 e+06$

$3.995 e+06$

$7.925 e+05$

FIGURE 12: Numerical fracture process (the average strain rate is $52 \mathrm{~s}^{-1}$ ).

Figure 9 presents a typical curve of stress equilibrium equations factor versus loading time received in this study by using pulse shaping technique. If $D \leq 0.05$, as can be seen from Figure 9, the stress within the specimen is uniform at 50 us when the half-sine waveform loading is adopted. When it is assumed that the failure strain is 5000 us at $100 / \mathrm{s}$ for rock, the total loading time before the failure is 100 us. It is clear that the stress distribution along the radius is uniform during the loading period, which is very important for SHPB experiment. While the rectangular waveform loading is adopted, good equilibrium effect is achieved when the time is above 125 us after the stress reaches its maximum (Figure 10).
4.2. Numerical Analysis on the Failure Process of Rock. The mechanical behavior of rock, including its fracture characteristics, has become more and more important in recent years [36].

The pressure loading shape is half-sine. The stress level is $150 \mathrm{MPa}$ and $250 \mathrm{MPa}$, respectively. The rising is $125 \mu$ s, and the duration is $250 \mu \mathrm{s}$. The tensile stress of $13.8 \mathrm{MPa}$ is set as failure point of the element in numerical simulation. The rock is gripped between incident bar and transmission bar, and the process of damage of the specimen is shown in Figures $11,12,13$, and 14 . It is clear that its main damage is mostly in the form of tensile splitting failure along the axial direction. There was no damage in the front-end unit of specimen in 


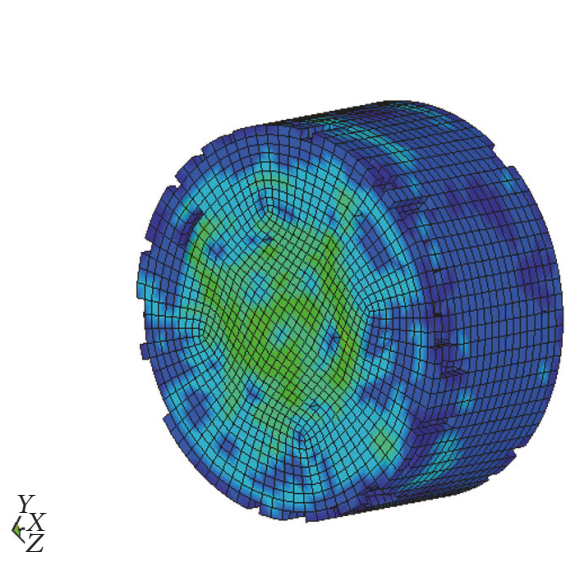

$130 \mu \mathrm{s}$

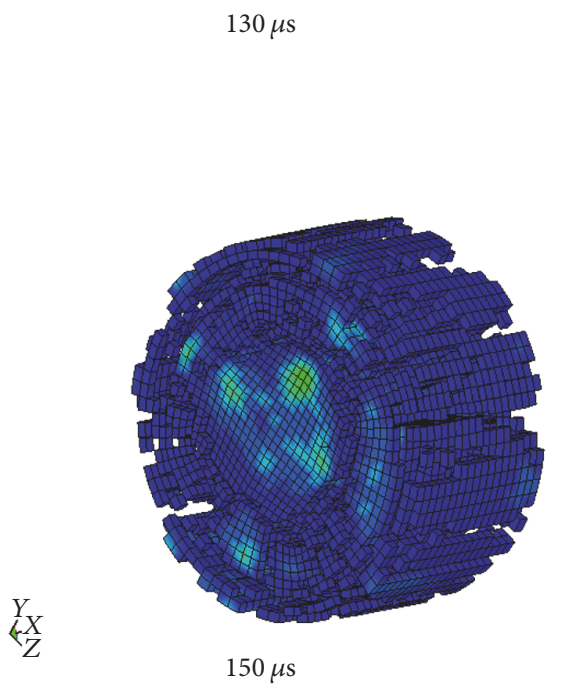

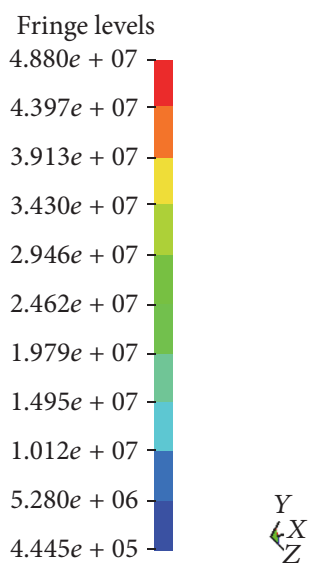

$Y$
$\forall X$
$Z$

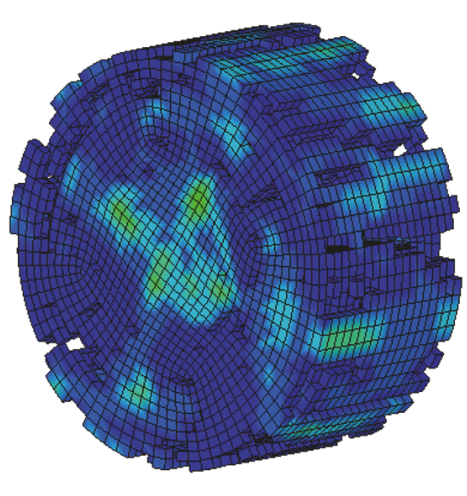

Fringe levels

$1.201 e+08$

$1.082 e+08$

$9.629 e+07$

$8.439 e+07$

$7.248 e+07$

$6.058 e+07$

$4.868 e+07$

$3.678 e+07$

$2.487 e+07$

$1.297 e+07$

$1.070 e+06$
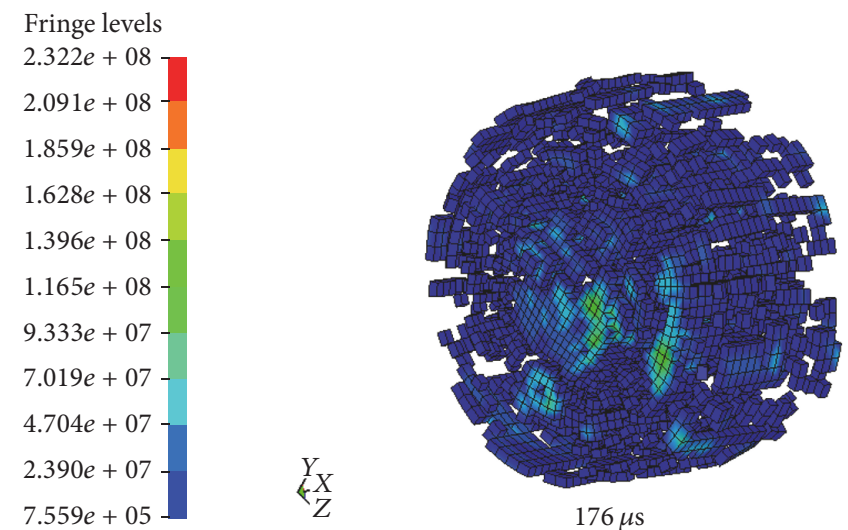

Fringe levels

$2.789 e+07$

$2.515 e+07$

$2.241 e+07$

$1.967 e+07$

$1.693 e+07$

$1.420 e+07$

$1.146 e+07$

$8.721 e+06-$

$5.983 e+06$

$3.246 e+06$

$5.079 e+05$

FIGURE 13: Numerical fracture process (the average strain rate is $130 \mathrm{~s}^{-1}$ ).

the initial loading stage, while some cracks developed at some certain locations, such as the sides, finally leading to specimen collapse. This is because the lateral face is free; when the compression wave converts into tensile wave after reflection, it easily leads to tensile failure for rock-like material, even if the tension is not so strong.

It is also observed from numerical results that the failure modes transformed from fragmentation to pulverization. With the increase of strain rate, the number of broken pieces increased, as shown in Figure 13. Figure 14 summarizes the process of damage in high-speed photographs for SHPB experiments, and it is evident that the main crack orientation is axial, that is, parallel to the direction of wave propagation.

Figures 15 and 16 show the photos of failure modes of specimens, which are similar to the simulation results (Figures 11 and 13). The failure strength (as can be seen from the stress versus strain profiles in Figure 17) of rock is shown to have positive strain rate sensitivity. These results are satisfactory, showing the strain rate's effect on the degree of fragmentation accurately.

\section{Conclusions}

Feasibility of rock dynamic properties by split-Hopkinson pressure bar (SHPB) was experimentally and numerically evaluated with ANSYS/LS-DYNA.

It is found that the time required to achieve a uniform stress state in a specimen for the half-sine incident pulse is noticeably shorter than that for the perfectly rectangular incident pulse. Therefore, the half-sine wave is an optimum incident pulse shape that can make the measured data reliable and valid.

The numerical modeling indicates the existence of some relationship between compressive fracture process and strain rate of rock material. This is similar to experimental investigation. It is also found that there is a good agreement between numerical stress-strain curves and experimental stress-strain curves. This study provides evidence that half-sine pulse decreases dispersion in wave propagation.

\section{Conflicts of Interest}

The authors declare that there are no conflicts of interest. 


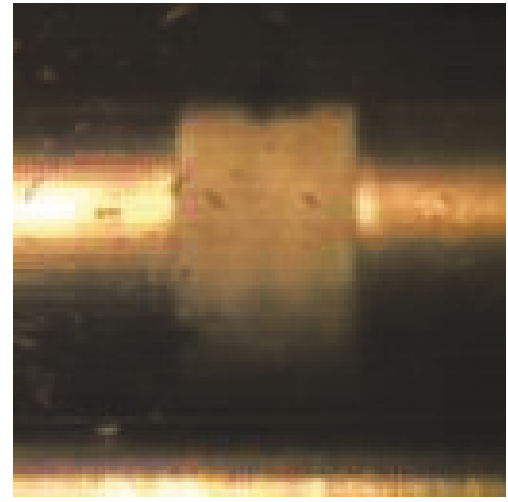

(1)

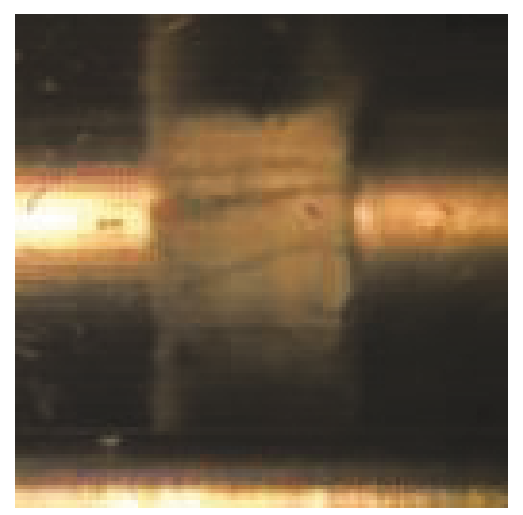

(4)

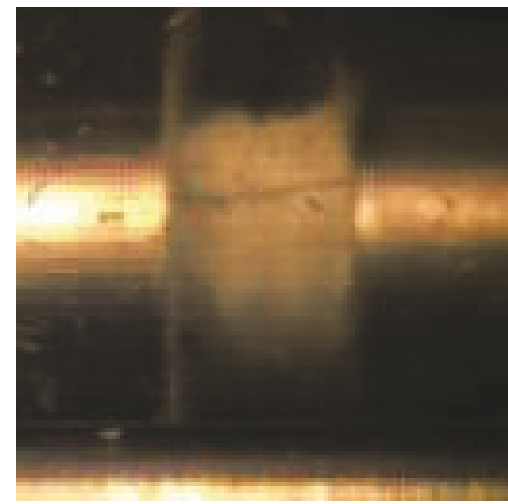

(2)

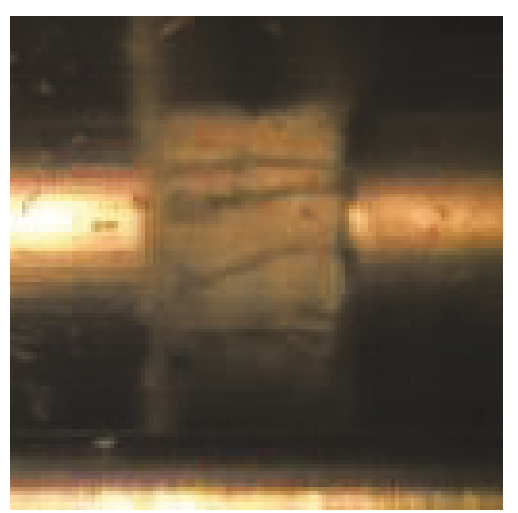

(5)

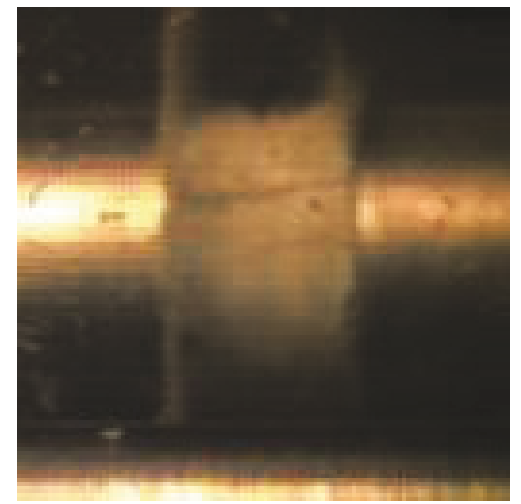

(3)

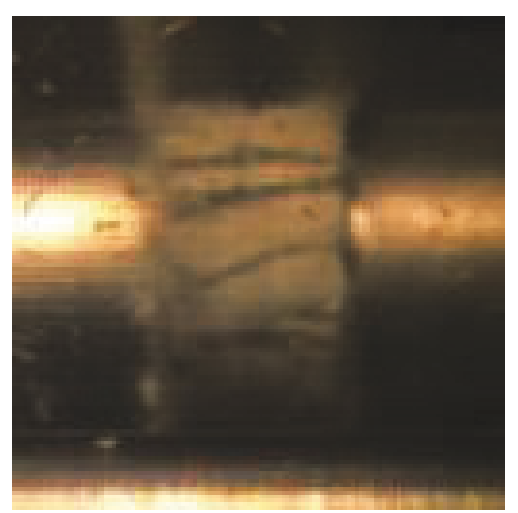

(6)

FIGURE 14: Photograph of fracture process from tests (the length-diameter ratio of specimen is 0.5 , and the average strain rate is $119 \mathrm{~s}^{-1}$ ).

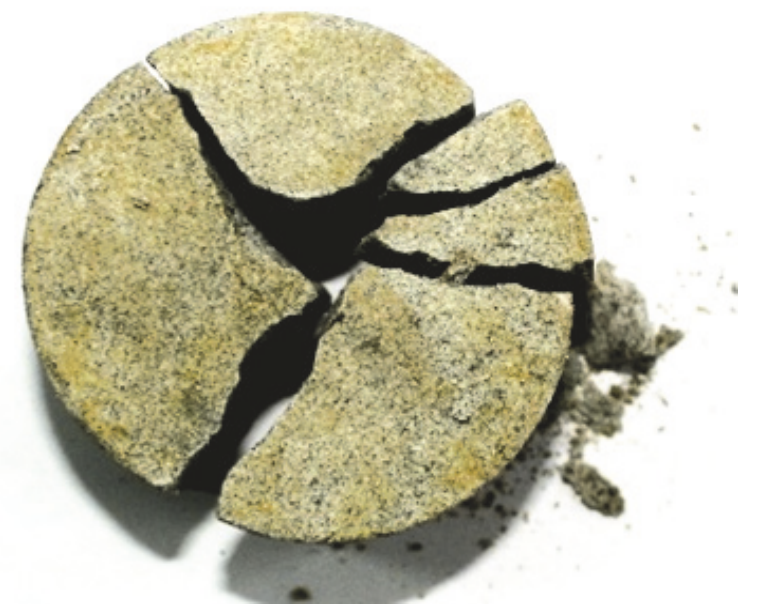

FIGURE 15: Failure modes of specimens in the SHPB test (the length-diameter ratio of specimen is 0.5 , and the average strain rate is $75.3 \mathrm{~s}^{-1}$ ). 


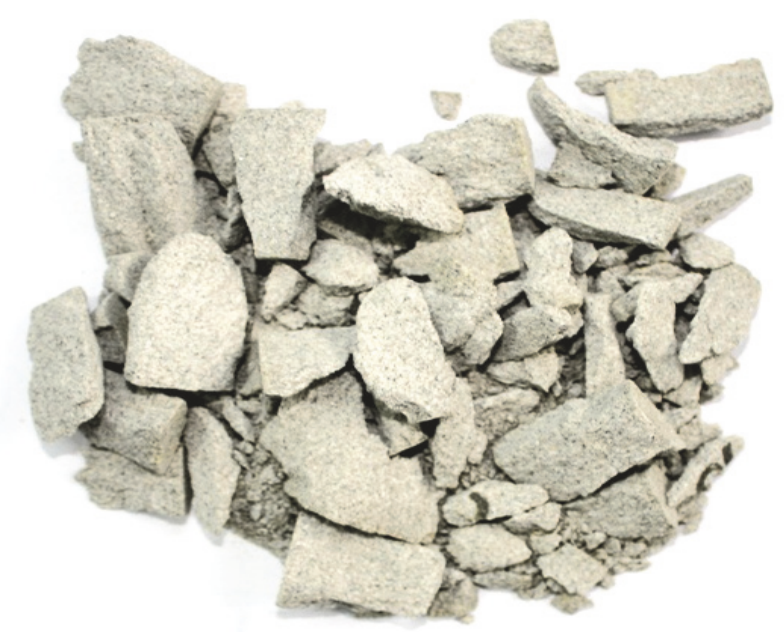

FIGURE 16: Failure modes of specimens in the SHPB test (the length-diameter ratio of specimen is 0.5 , and the average strain rate is $162 \mathrm{~s}^{-1}$ ).

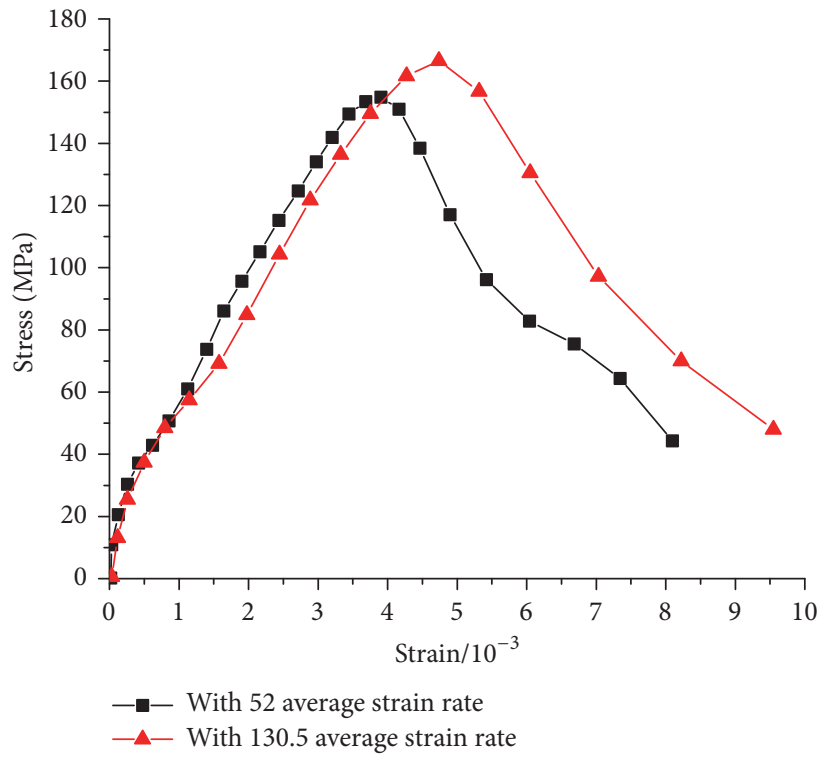

(a) Numerical results

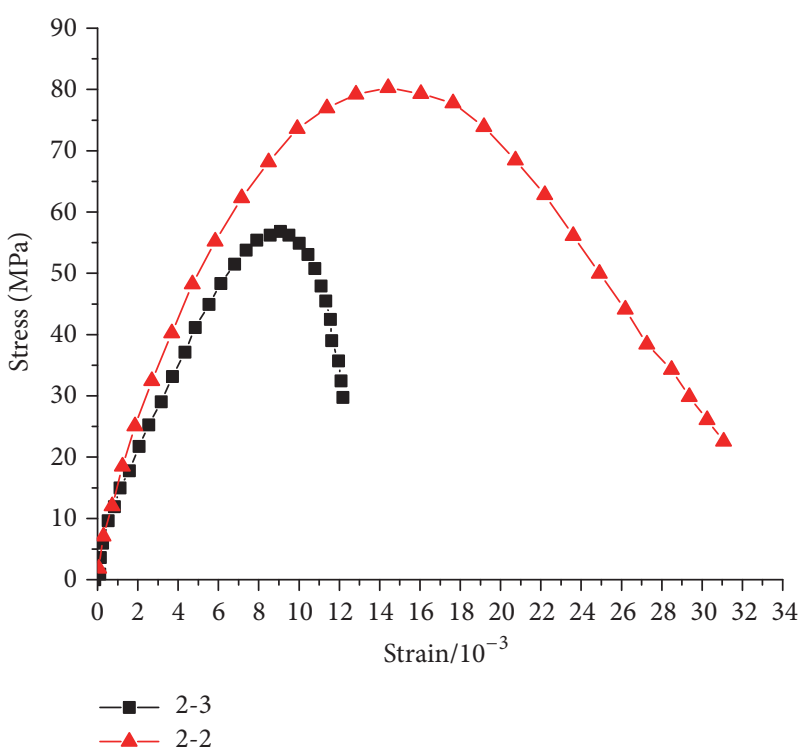

(b) Test results

FIGURE 17: Stress-strain curves.

\section{Acknowledgments}

The study reported in the paper is supported by National Natural Science Foundation of China (51504044 and 51404126), the Research Fund of Chongqing Basic Science and CuttingEdge Technology Special Projects (cstc2016jcyjA1861), China Postdoctoral Science Foundation (2015M570607), and the Independent Subject of State Key Laboratory of Coal Mine Disaster Dynamics and Control (2011DA105287-MS201503).

\section{References}

[1] J. S. Rinehart, "Dynamic fracture strength of rocks," in Proceedings of the 7th US Symposium on Rock Mechanics, pp. 205213, Society of Mining, Metallurgical and Petroleum Engineers, Pennsylvania, Pa, USA, 1965.
[2] A. Kumar, "The effect of stress rate and temperature on the strength of basalt and granite," Geophysics, vol. 33, no. 3, pp. 501$510,1968$.

[3] U. S. Lindholm, L. M. Yeakley, and A. Nagy, "The dynamic strength and fracture properties of dresser basalt," International Journal of Rock Mechanics and Mining Sciences \& Geomechanics Abstracts, vol. 11, no. 5, pp. 181-191, 1974.

[4] T. L. Blanton, "Effect of strain rates from $10^{-2}$ to $10 \mathrm{sec}^{-1}$ in triaxial compression tests on three rocks," International Journal of Rock Mechanics and Mining Sciences \& Geomechanics Abstracts, vol. 18, no. 1, pp. 47-62, 1981.

[5] Z. P. Bažant, B. Shang-Ping, and G. Ravindra, "Fracture of rock: effect of loading rate," Engineering Fracture Mechanics, vol. 45, no. 3, pp. 393-398, 1993.

[6] X. B. Li, T. S. Lok, and J. Zhao, "Dynamic characteristics of granite subjected to intermediate loading rate," Rock Mechanics and Rock Engineering, vol. 38, no. 1, pp. 21-39, 2005. 
[7] H. B. Li, J. Zhao, and T. J. Li, "Micromechanical modelling of the mechanical properties of a granite under dynamic uniaxial compressive loads," International Journal of Rock Mechanics and Mining Sciences, vol. 37, no. 6, pp. 923-935, 2000.

[8] L. Dong, J. Wesseloo, Y. Potvin, and X. Li, "Discrimination of mine seismic events and blasts using the fisher classifier, naive bayesian classifier and logistic regression," Rock Mechanics and Rock Engineering, vol. 49, no. 1, pp. 183-211, 2016.

[9] L. Dong, X. Li, and G. Xie, "Nonlinear methodologies for identifying seismic event and nuclear explosion using random forest, support vector machine, and naive Bayes classification," Abstract and Applied Analysis, vol. 2014, Article ID 459137, 8 pages, 2014.

[10] F. Dai, S. Huang, K. Xia, and Z. Tan, "Some fundamental issues in dynamic compression and tension tests of rocks using split Hopkinson pressure bar," Rock Mechanics and Rock Engineering, vol. 43, no. 6, pp. 657-666, 2010.

[11] Y. Xu, F. Dai, N. W. Xu, and T. Zhao, "Numerical investigation of dynamic rock fracture toughness determination using a semicircular bend specimen in split hopkinson pressure bar testing," Rock Mechanics and Rock Engineering, vol. 49, no. 3, pp. 731-745, 2016.

[12] Z. Wen, X. Wang, L. Chen, G. Lin, and H. Zhang, "Size effect on acoustic emission characteristics of coal-rock damage evolution," Advances in Materials Science and Engineering, vol. 2017, Article ID 3472485, 8 pages, 2017.

[13] F. Dai, Y. Xu, T. Zhao, N.-W. Xu, and Y. Liu, "Loading-ratedependent progressive fracturing of cracked chevron-notched Brazilian disc specimens in split Hopkinson pressure bar tests," International Journal of Rock Mechanics and Mining Sciences, vol. 88, pp. 49-60, 2016.

[14] X. Liu, F. Dai, R. Zhang, and J. Liu, "Static and dynamic uniaxial compression tests on coal rock considering the bedding directivity," Environmental Earth Sciences, vol. 73, no. 10, pp. 5933-5949, 2015.

[15] L. D. Bertholf and C. H. Karnes, "Two-dimensional analysis of the split hopkinson pressure bar system," Journal of the Mechanics and Physics of Solids, vol. 23, no. 1, pp. 1-19, 1975.

[16] Z.-J. Wen, M. Rinne, Z. Song, Z.-Z. Han, and J.-H. Wen, "Research on modelling of spatial dynamic structural mechanics and spatio-temporal evolution of coal mine stopes," Tehnicki Vjesnik, vol. 22, no. 3, pp. 607-613, 2015.

[17] Z. Wen, X. Wang, Y. Tan, H. Zhang, W. Huang, and Q. Li, "A study of rockburst hazard evaluation method in coal mine," Shock and Vibration, vol. 2016, Article ID 8740868, 9 pages, 2016.

[18] S. F. Sun, X. T. Xu, and H. P. Li, "Numerical simulation of effects of specimen size and shape in SHPB experiment," Chinese Journal of Hefei University of Technology, vol. 31, no. 9, pp. 15091512, 2008.

[19] T. S. Lok, X. B. Li, D. Liu, and P. J. Zhao, "Testing and response of large diameter brittle materials subjected to high strain rate," Journal of Materials in Civil Engineering, vol. 14, no. 3, pp. 262269, 2002.

[20] X. He and C. Xu, "Specific energy as an index to identify the critical failure mode transition depth in rock cutting," Rock Mechanics and Rock Engineering, vol. 49, no. 4, pp. 1461-1478, 2016.

[21] Y. Xu, F. Dai, N.-W. Xu, T. Zhao, and C. Zhou, "Discrete element simulation of dynamic semi-circular bend flexure tests of rocks using split Hopkinson pressure bar," Arabian Journal of Geosciences, vol. 9, no. 9, article 543, 2016.
[22] Z. Zhou, X. Li, Y. Zou, Y. Jiang, and G. Li, "Dynamic Brazilian tests of granite under coupled static and dynamic loads," Rock Mechanics and Rock Engineering, vol. 47, no. 2, pp. 495-505, 2014.

[23] X. B. Li, D. S. Gu, and H. H. Lai, "On the reasonable loading stress waveforms determined by dynamic stress-strain curves of rocks by SHPB," Chinese Explosion and Shock Waves, vol. 13, no. 2, pp. 125-130, 1993.

[24] X. B. Li, T. S. Lok, J. Zhao, and P. J. Zhao, "Oscillation elimination in the Hopkinson bar apparatus and resultant complete dynamic stress-strain curves for rocks," International Journal of Rock Mechanics and Mining Sciences, vol. 37, no. 7, pp. 1055-1060, 2000.

[25] Z. Wen, Y. Tan, Z. Han, and F. Meng, "Construction of timespace structure model of deep stope and stability analysis," Polish Journal of Environmental Studies, vol. 25, no. 6, pp. 26332640, 2016.

[26] M. K. C. Roberts and R. K. Brummer, "Supportrequirementsin rockburst conditions," Journal of the South African Institute of Mining and Metallurgy, vol. 88, no. 3, pp. 97-104, 1988.

[27] T. J. Holmquist, G. R. Johnson, and W. H. Cook, "A computational constitutive model for concreted to large strains, high strain rates, and high pressures," in Proceeding of the Fourteenth International Symposium on Ballistics, pp. 591-600, Quebec, Canada, 1995.

[28] “Ls-dyna Keyword User's Manual, Version 970," LSTC, April 2003.

[29] Y.-S. Tai and C.-C. Tang, "Numerical simulation: the dynamic behavior of reinforced concrete plates under normal impact," Theoretical and Applied Fracture Mechanics, vol. 45, no. 2, pp. 117-127, 2006.

[30] Z. Tang and L. Wang, "Computational data processing system of SHPB," Explosion Shock Waves, vol. 6, no. 4, pp. 320-327, 1986.

[31] H. Zhao, G. Gary, and J. R. Klepaczko, "On the use of a viscoelastic split Hopkinson pressure bar," International Journal of Impact Engineering, vol. 19, no. 4, pp. 319-330, 1997.

[32] R. Merle and H. Zhao, "On the errors associated with the use of large diameter SHPB, correction for radially non-uniform distribution of stress and particle velocity in SHPB testing," International Journal of Impact Engineering, vol. 32, no. 12, pp. 1964-1980, 2006.

[33] H. Zhao and G. Gary, "On the use of SHPB techniques to determine the dynamic behavior of materials in the range of small strains," International Journal of Solids and Structures, vol. 33, no. 23, pp. 3363-3375, 1996.

[34] X. B. Li and D. S. Gu, "Effective method of eliminating the oscillation of rock dynamic stress-strain-strain rate curves," Journal of Central South University Technology, vol. 36, pp. 457460, 1995.

[35] U. Zencker and R. Clos, "Limiting conditions for compression testing of flat specimens in the split Hopkinson pressure bar," Experimental Mechanics, vol. 39, no. 4, pp. 343-348, 1999.

[36] W. Goldsmith, J. L. Sackmn, and C. Ewert, "Static and dynamic fracture strength of barre granite," International Journal of Rock Mechanics and Mining Sciences \& Geomechanics Abstracts, vol. 13, no. 11, pp. 303-309, 1976. 

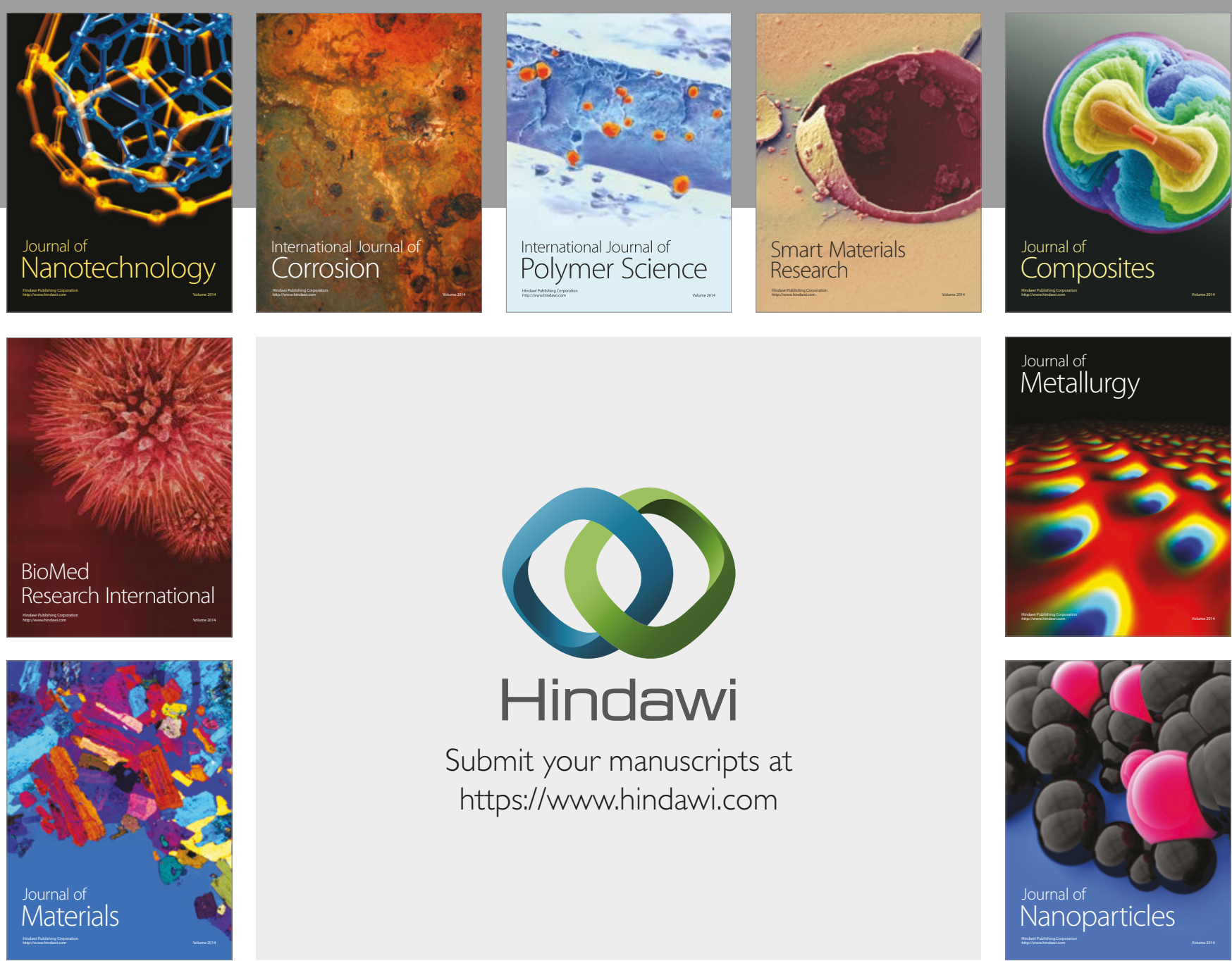

\section{Hindawi}

Submit your manuscripts at

https://www.hindawi.com
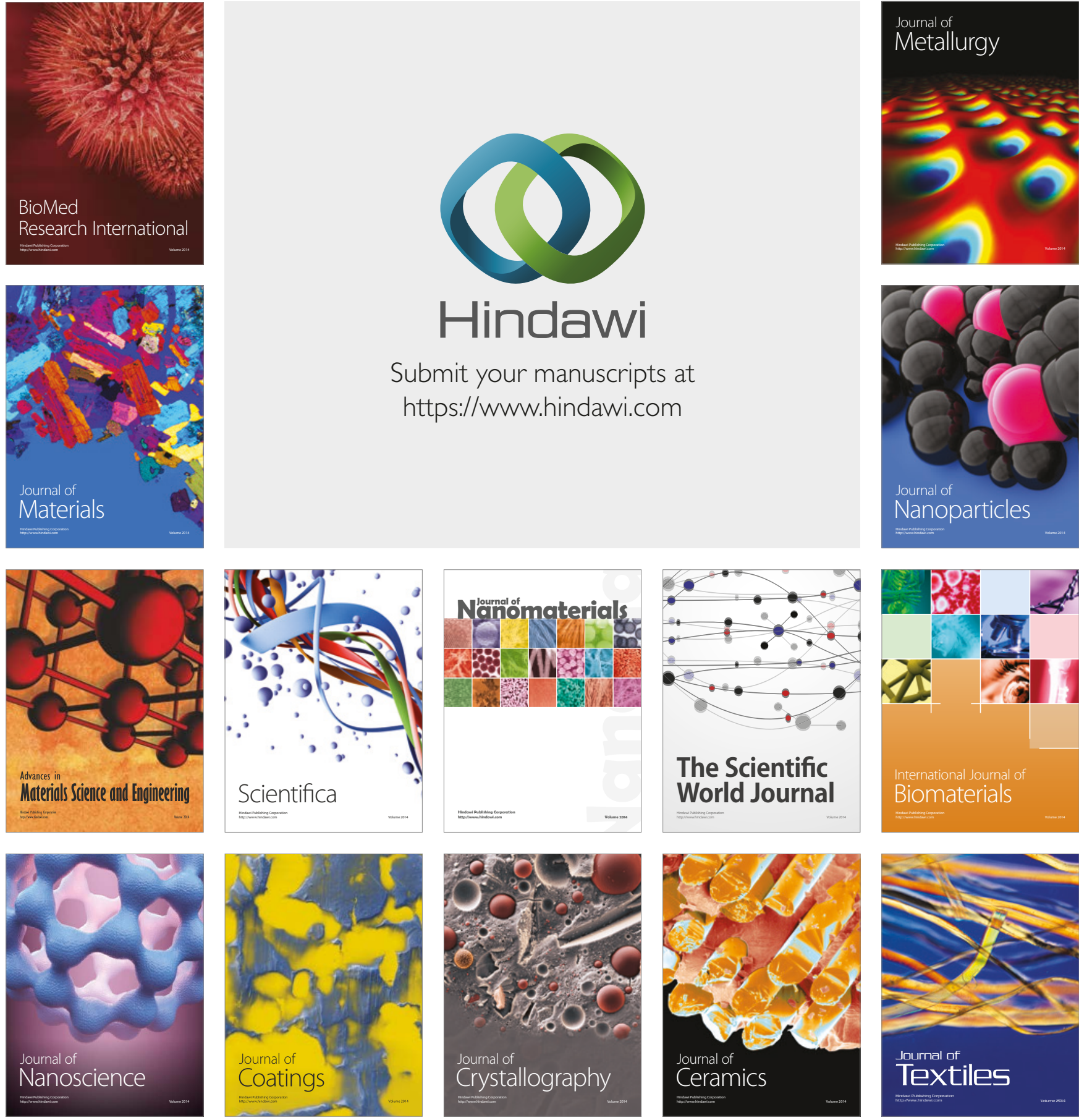

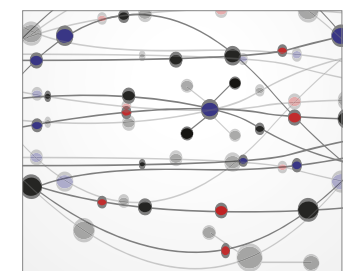

The Scientific World Journal
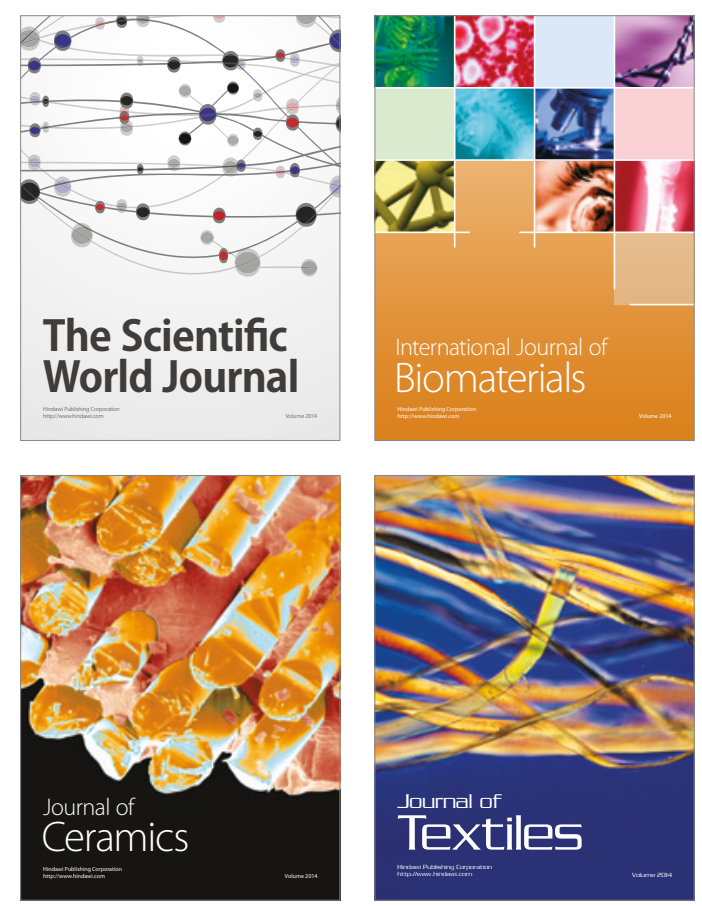